\title{
Atherosclerotic diseases and lung cancer - a ten-year cross-sectional study in Cyprus
}

Irene Rethemiotaki

Department of Production Engineering and Management, Technical University of Crete, Chania, Greece

Submitted: 10 April 2020

Accepted: 25 April 2020

Arch Med Sci Atheroscler Dis 2020; 5: : e72-e78

DOI: https://doi.org/10.5114/amsad.2020.95570

Copyright $\odot 2020$ Termedia \& Banach

\section{Abstract}

Introduction: The main purpose of this work is to study atherosclerotic diseases and lung cancer in Cyprus during the period 2007-2017 with the aim of finding not only the atherosclerotic diseases with the highest risk but also a possible association between these diseases and lung cancer.

Material and methods: The statistical methods used to extract the results of this work are Student's t-test and one-way analysis of variance (ANOVA), in order to check the statistical significance of atherosclerotic diseases with regard to the characteristics of the patients. Additionally, a multiple logistic regression analysis was used with the aim of finding the disease with the highest risk. Pearson's $r$ was used to find a possible association between atherosclerotic diseases and lung cancer.

Results: As specified by multiple logistic regression analysis, the atherosclerotic diseases with the highest risk of death are intracranial haemorrhage (OR $=17.3)$, heart failure $(O R=3.29)$, and stroke $(O R=3.02)$, with females having higher risk compared to men. Moreover, a statistically significant relation was found between heart failure and cerebral infarction with lung cancer.

Conclusions: The results of this work highlight the statistically significant characteristics of patients with atherosclerotic diseases and identify the risk of death according to the type of the disease. A link between these diseases and cancer was also identified.

Key words: cancer, atherosclerotic diseases, malignant neoplasms.

\section{Introduction}

Atherosclerotic diseases are the leading cause of death worldwide, accounting for 17.9 million deaths each year [1]. Some of the processes involved in atherosclerosis are lipid disorders, thrombosis, oxidative stress, and endothelial dysfunction [2]. Risk factors include cigarette smoking, diabetes mellitus, adiposity, hypertension, and blood cholesterol. More specifically, it has been found that smokers are 1.7-5.6 times more likely to be at risk for atherosclerotic diseases than non-smokers [3-5]. Moreover, individuals with diabetes mellitus have twice the risk of mortality, because a $1 \%$ increase in haemoglobin $A_{1 c}\left(H_{b A_{1 c}}\right)$ has been shown to increase the risk of atherosclerotic heart disease by $50 \%$ [6-9]. Adiposity poses a high risk of atherosclerotic diseases; each $1 \mathrm{~kg} / \mathrm{m}^{2}$ increase above the level of $25 \mathrm{~kg} / \mathrm{m}^{2}$ in body mass index (BMI) causes an increase of $8 \%$ in atherosclerotic heart disease mortality $[10,11]$. Hypertension has been proven to increase the risk of atherosclerotic diseases; any

\author{
Corresponding author: \\ Irene Rethemiotaki \\ Department of Production \\ Engineering \\ and Management \\ Technical University \\ of Crete \\ Chania, Greece \\ E-mail: eirinireth@yahoo.gr
}


$20 \mathrm{~mm} \mathrm{Hg}$ increase in usual systolic blood pressure and $10 \mathrm{~mm} \mathrm{Hg}$ increase in diastolic blood pressure doubles that risk [12-14]. Finally, blood cholesterol plays a key role in the emergence of atherosclerotic heart disease [15-17]. More precisely, there is a strong positive association between non-high-density lipoprotein (non-HDL) cholesterol with atherosclerotic heart disease mortality predominantly in the age group of 50-59 years, while each $38.7 \mathrm{mg} / \mathrm{dl}$ decrease in normal total cholesterol is associated with a $42 \%$ lower risk of atherosclerotic heart disease mortality [15].

Prior studies identified a strong association between lung cancer and atherosclerotic diseases $[18,19]$. Patients with lung cancer have an $89 \%$ increased risk of developing atherosclerotic heart disease compared to those not afflicted with cancer. The underlying mechanisms by which atherosclerosis is associated with cancer are chronic inflammation, oxidative stress, altered telomere length, and clonal haematopoiesis [20-22]. It is of the utmost importance to acknowledge the multifaceted interactions that lead to both neoplasia and atherosclerosis, which in turn reflect the responsibility of underlying conditions such as essential (primary) hypertension for the high risk of death from these diseases.

For this purpose, this work studies atherosclerotic diseases in Cyprus during the period 20072017 in order to identify which type has the highest death risk, as well as a possible association with lung cancer.

\section{Material and methods}

The data used in this work come from the Republic of Cyprus. The target population of the analysis is the 37,628 confirmed cases of patients with atherosclerotic diseases who were hospitalised in Cyprus during 2007-2017.

\section{Statistical analysis}

The statistical methods used to extract the results of this work are Student's t-test and oneway analysis of variance (ANOVA) for continuous variables, to check the statistical significance of the characteristics of patients such as gender and age. Factors that ascertain the prevalence of death from atherosclerotic diseases, as well as the severity of each type of disease, were evaluated by using multiple logistic regression analysis. To better estimate the type of disease with the highest risk of death, data from patients with a new diagnosis of an atherosclerotic disease was compared to a matched cohort group of patients who had died from this disease. The data were weighted before analysis. Predictors were presented using the OR and 95\% confidence intervals, and $p<0.05$ was considered as statistically significant. Pearson's $r$ was used for the relationship between atherosclerotic diseases and lung cancer for the years 2007-2017. The statistical analysis of this manuscript was performed by using the software package IBMSPSS 25 for Windows.

\section{Results}

To test the zero hypotheses that the mean of the patients did not differ in accordance with their characteristics, Student's t-test and oneway analysis of variance (ANOVA) were used. As shown in Table I, there is a statistically significant difference in the number of patients with athero-

Table I. Atherosclerotic diseases: Cyprus 2007-2017. Student $t$-test

\begin{tabular}{|lccc|}
\hline Variable & Males & Females & $P$-value \\
\hline Chronic rheumatic heart disease & 107 & 171 & $<0.05$ \\
\hline Essential (primary) hypertension & 480 & 395 & $<0.05$ \\
\hline Acute myocardial infarction & 5727 & 1216 & $<0.05$ \\
\hline Pulmonery embolism & 301 & 439 & $<0.05$ \\
\hline Conduction disorders and cardiac arrhythmias & 6950 & 5697 & $<0.05$ \\
\hline Heart failure & 4490 & 2494 & $<0.05$ \\
\hline Intracranial haemorrhage & 676 & 710 & $<0.05$ \\
\hline Cerebral infarction & 384 & 340 & $<0.05$ \\
\hline $\begin{array}{l}\text { Stroke, not specified as haemorrhage or } \\
\text { infarction }\end{array}$ & 3321 & 3022 & $<0.05$ \\
\hline Atherosclerosis & 62 & 53 & $<0.05$ \\
\hline Arterial embolism and thrombosis & 202 & 121 & $<0.05$ \\
\hline Overall & 22981 & 14647 & $<0.05$ \\
\hline
\end{tabular}


Table II. Atherosclerotic diseases by age: Cyprus 2007-2017. One-way ANOVA test

\begin{tabular}{|c|c|c|c|c|c|c|}
\hline Variable & $<1$ & $1-14$ & $15-44$ & $45-64$ & $\geq 65$ & $P$-value \\
\hline Chronic rheumatic heart disease & $0(0 \%)$ & $1(0.4 \%)$ & $24(9.7 \%)$ & $98(39.5 \%)$ & $125(50.4 \%)$ & $<0.05$ \\
\hline Essential (primary) hypertension & $17(2.1 \%)$ & $68(8.4 \%)$ & $147(18.1 \%)$ & $267(33 \%)$ & $311(38.4 \%)$ & $<0.05$ \\
\hline Acute myocardial infarction & $0(0 \%)$ & $31(0.5 \%)$ & $666(11.1 \%)$ & $2948(49.1 \%)$ & $2364(39.3 \%)$ & $<0.05$ \\
\hline Pulmonery embolism & $0(0 \%)$ & $12(1.9 \%)$ & $103(16.5 \%)$ & $178(28.6 \%)$ & $330(53 \%)$ & $<0.05$ \\
\hline $\begin{array}{l}\text { Conduction disorders and } \\
\text { cardiac arrhythmias }\end{array}$ & $47(0.4 \%)$ & $168(1.5 \%)$ & $1041(9.3 \%)$ & $3421(30.4 \%)$ & $6563(58.4 \%)$ & $<0.05$ \\
\hline Heart failure & $27(0.4 \%)$ & $31(0.5 \%)$ & $201(3.3 \%)$ & $1432(23.8 \%)$ & $4322(71.9 \%)$ & $<0.05$ \\
\hline Intracranial haemorrhage & $5(0.3 \%)$ & $22(1.5 \%)$ & $169(11.8 \%)$ & $439(30.7 \%)$ & $794(55.6 \%)$ & $<0.05$ \\
\hline Cerebral infarction & $0(0 \%)$ & $0(0 \%)$ & $30(5.5 \%)$ & $121(22.2 \%)$ & $393(72.2 \%)$ & $<0.05$ \\
\hline Stroke & $1(0 \%)$ & $29(0.5 \%)$ & $303(5.2 \%)$ & $1758(30.1 \%)$ & $3745(64.2 \%)$ & $<0.05$ \\
\hline Atherosclerosis & $0(0 \%)$ & $2(1.9 \%)$ & $9(8.7 \%)$ & $29(28.2 \%)$ & $63(61.2 \%)$ & $<0.05$ \\
\hline $\begin{array}{l}\text { Arterial embolism and } \\
\text { thrombosis }\end{array}$ & $0(0 \%)$ & $1(0.3 \%)$ & $24(7.7 \%)$ & $100(32.2 \%)$ & $186(59.8 \%)$ & $<0.05$ \\
\hline Overall & $96(0.4 \%)$ & $333(1.3 \%)$ & $2356(8.9 \%)$ & $8802(33.3 \%)$ & $14,861(56.2 \%)$ & $<0.05$ \\
\hline
\end{tabular}

sclerotic diseases in relation to gender, predominantly in males (61.1\%), in the total number of atherosclerotic diseases. More specifically, essential (primary) hypertension (54.9\%), acute myocardial infarction (82.5\%), conduction disorders and cardiac arrhythmias (55\%), heart failure (64.3\%), cerebral infarction (53\%), stroke that not specified as haemorrhage or infarction (52.4\%), atheroscle-

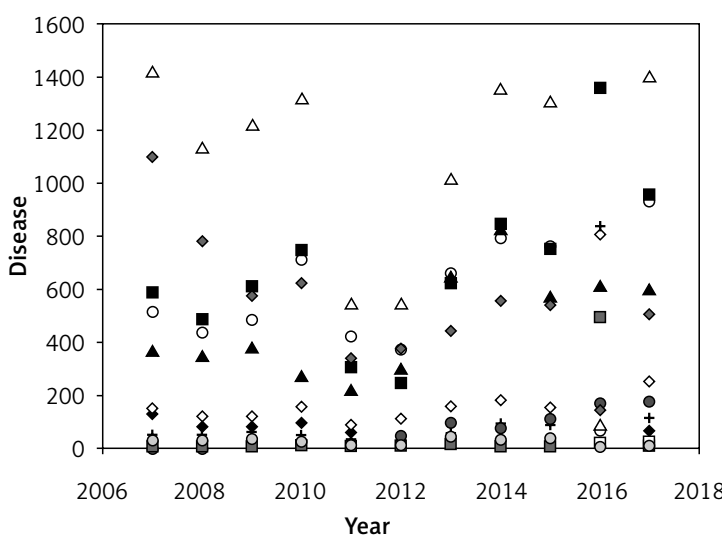

$\square$ Chronic rheumatic heart disease

- Essential (primary) hypertension

o Acute myocardial infarction

+ Pulmonery embolism

$\Delta$ Conduction disorders and cardiac arrhythmias

- Heart failure

$\diamond$ Intracranial haemorrhage

- Cerebral infarction

$\diamond$ Stroke, not specified as haemorrhage or infarction

$\square$ Atherosclerosis

o Arterial embolism and thrombosis

$\Delta$ Lung cancer

Figure 1. Trends in atherosclerotic diseases and lung cancer during the years 2007-2017 in Cyprus rosis (53.9\%), and arterial embolism and thrombosis $(62.5 \%)$ prevail mainly in males. While chronic rheumatic heart disease (61.5\%), pulmonary embolism (59.3\%), and intracranial haemorrhage (42.1\%) predominate in females. As shown in Table II, there is a statistically significant difference in the number of patients with atherosclerotic diseases in relation to age, predominantly in the age group of 65 years and over, in all atherosclerotic diseases (56.2\%), except for acute myocardial infarction, which was observed mainly in the age group of 45-64 years (49.1\%).

Figure 1 represents the trends in all atherosclerotic diseases and lung cancer during the years 2007-2017 in Cyprus. Although there was a decline in the incidence of these diseases in 2011 and 2012, there was an increase in the following years, with conduction disorders and cardiac arrhythmias, heart failure, and acute myocardial infarction occupying the top three in 2017.

Tables III and IV represent the multiple logistic regression analysis and odds ratios in order to find the atherosclerotic diseases with the highest death risk. Based on multiple logistic regression, the risk of death from intracranial haemorrhage is the highest $(O R=17.3)$, with no statistical difference between the two genders. The risk of death is three times higher in heart failure $(O R=3.29)$ and stroke $(\mathrm{OR}=3.02)$ not specified as haemorrhage or infarction, with females having higher risk than males. Conduction disorders and cardiac arrhythmias $(\mathrm{OR}=3.13)$ also have a three-times higher risk of death, with no statistical difference between the two genders. Subsequently, in pulmonary embolism $(\mathrm{OR}=2.72)$ the risk of death 
Table III. Atherosclerotic diseases: Cyprus 2007-2017. Multivariate logistic regression.

\begin{tabular}{|c|c|c|c|c|}
\hline Variable & Alive & Dead & Odds ratio $(95 \% \mathrm{Cl})$ & $P$-value \\
\hline Chronic rheumatic heart disease: & & & & $>0.05$ \\
\hline Female & 165 & 2 & $1.0(0.2-4.4)$ & \\
\hline Male & 104 & 3 & 1.0 (ref.) & \\
\hline Essential (primary) hypertension: & & & & $<0.05$ \\
\hline Female & 385 & 2 & $14.6(14.4-15.9)$ & \\
\hline Male & 469 & 0 & 1.0 (ref.) & \\
\hline Acute myocardial infarction: & & & & $<0.05$ \\
\hline Female & 1.086 & 114 & $4.0(3.1-5.2)$ & \\
\hline Male & 5.501 & 141 & 1.0 (ref.) & \\
\hline Pulmonery embolism: & & & & $>0.05$ \\
\hline Female & 399 & 5 & $1.1(0.6-2.0)$ & \\
\hline Male & 277 & 22 & 1.0 (ref.) & \\
\hline Conduction disorders and cardiac arrhythmias: & & & & $>0.05$ \\
\hline Female & 5.084 & 503 & $0.9(0.8-1.2)$ & \\
\hline Male & 6.205 & 630 & 1.0 (ref.) & \\
\hline Heart failure: & & & & $<0.05$ \\
\hline Female & 2.153 & 284 & $1.4(1.2-1.6)$ & \\
\hline Male & 4.036 & 370 & 1.0 (ref.) & \\
\hline Intracranial haemorrhage: & & & & $>0.05$ \\
\hline Female & 591 & 115 & $1.0(0.7-1.3)$ & \\
\hline Male & 817 & 155 & 1.0 (ref.) & \\
\hline Cerebral infarction: & & & & $>0.05$ \\
\hline Female & 321 & 17 & $1.0(0.5-1.9)$ & \\
\hline Male & 364 & 19 & 1.0 (ref.) & \\
\hline Stroke, not specified as haemorrhage or infarction: & & & & $<0.05$ \\
\hline Female & 2.674 & 324 & $1.6(1.3-1.9)$ & \\
\hline Male & 3.066 & 233 & 1.0 (ref.) & \\
\hline Atherosclerosis: & & & & $>0.05$ \\
\hline Female & 50 & 3 & $3.7(0.3-36.2)$ & \\
\hline Male & 61 & 1 & 1.0 (ref.) & \\
\hline Arterial embolism and thrombosis: & & & & $>0.05$ \\
\hline Female & 115 & 5 & $1.7(0.5-6.0)$ & \\
\hline Male & 197 & 5 & 1.0 (ref.) & \\
\hline
\end{tabular}

is two times higher, with no statistical difference between the two genders. In cerebral infraction, acute myocardial infarction, atherosclerosis, arterial embolism and thrombosis, and chronic rheumatic heart disease there is no statistically significant risk of death compared to other ath- erosclerotic diseases. Comparing the two genders, the risk of death in the acute myocardial infarction is four times higher in females $(O R=4.0)$. Finally, in essential (primary) hypertension $(O R=0.07)$ the risk of death is lower than the other atherosclerotic diseases and occurs mainly in females. 
Table IV. Atherosclerotic diseases: Cyprus 2007-2017. Multivariate logistic regression

\begin{tabular}{|lcccc|}
\hline Variable & Alive & Dead & Odds ratio (95\% Cl) & $P$-value \\
\hline Chronic rheumatic heart disease & 269 & 5 & $0.92(0.36-2.38)$ & $>0.05$ \\
\hline Essential (primary) hypertension & 854 & 2 & $0.07(0.01-0.33)$ & $<0.05$ \\
\hline Acute myocardial infarction & 6.587 & 255 & $1.20(0.63-2.29)$ & $>0.05$ \\
\hline Pulmonery embolism & 676 & 27 & $2.72(1.37-5.39)$ & $<0.05$ \\
\hline Conduction disorders and cardiac arrhythmias & 11.289 & 1.133 & $3.13(1.66-5.89)$ & $<0.05$ \\
\hline Heart failure & 6.189 & 654 & $3.29(1.74-6.22)$ & $<0.05$ \\
\hline Intracranial haemorrhage & 1.408 & 270 & $17.3(18.0-19.2)$ & $<0.05$ \\
\hline Cerebral infarction & 685 & 36 & $1.64(0.80-3.34)$ & $>0.05$ \\
\hline Stroke, not specified as haemorrhage or infarction & 5740 & 557 & $3.02(1.60-5.71)$ & $<0.05$ \\
\hline Atherosclerosis & 111 & 4 & $1.12(0.34-3.65)$ & $>0.05$ \\
\hline Arterial embolism and thrombosis & 312 & 10 & $1.0($ ref. $)$ & $>0.05$ \\
\hline
\end{tabular}

Table V. Pearson's correlation coefficient

\begin{tabular}{|llc|}
\hline Variable & \multicolumn{2}{c|}{ Lung cancer } \\
\cline { 2 - 3 } & $\begin{array}{c}\text { Pearson's } \\
\text { correlation } r\end{array}$ & $P$-value \\
\hline Lung cancer & 1 & \\
\hline $\begin{array}{l}\text { Chronic rheumatic heart } \\
\text { disease }\end{array}$ & 0.08 & $>0.05$ \\
\hline $\begin{array}{l}\text { Essential (primary) } \\
\text { hypertension }\end{array}$ & -0.18 & $>0.05$ \\
\hline Acute myocardial infarction & 0.34 & $>0.05$ \\
\hline Pulmonery embolism & 0.32 & $>0.05$ \\
\hline $\begin{array}{l}\text { Conduction disorders and } \\
\text { cardiac arrhythmias }\end{array}$ & 0.15 & $>0.05$ \\
\hline Heart failure & 0.64 & $<0.05$ \\
\hline Intracranial haemorrhage & 0.37 & $>0.05$ \\
\hline Cerebral infarction & 0.68 & $<0.05$ \\
\hline $\begin{array}{l}\text { Stroke, not specified as } \\
\text { haemorrhage or infarction }\end{array}$ & -0.20 & $>0.05$ \\
\hline Atherosclerosis & 0.25 & $>0.05$ \\
\hline $\begin{array}{l}\text { Arterial embolism and } \\
\text { thrombosis }\end{array}$ & 0.16 & $>0.05$ \\
\hline
\end{tabular}

Table $V$ represents the Pearson's $r$ among the total number of atherosclerotic diseases and lung cancer patients for the years 2007 to 2017. As shown in Table $\mathrm{V}$, the incidence of lung cancer is statistically significant with heart failure and cerebral infarction $(p<0.05)$. Pearson's $r$ between the total cases of lung cancer patients and cerebral infarction as well as heart failure patients is 0.68 and 0.64 , respectively, which indicates a link between these diseases and lung cancer.

Figure 2 shows the odds ratios for the risk of death from atherosclerotic diseases. As can be seen, intracranial haemorrhage ranks first, followed by heart failure, conduction disorders and cardiac arrhythmias, stroke, not specified as haemorrhage or infarction, and pulmonary embolism.

\section{Discussion}

It is worth highlighting that although atherosclerotic diseases occur predominantly in males (61.1\%) over 65 years of age, except acute myocardial infarction, which occurs in the age group of 45-64 years, females proved to have a higher risk of death than males. This is due to the rela-

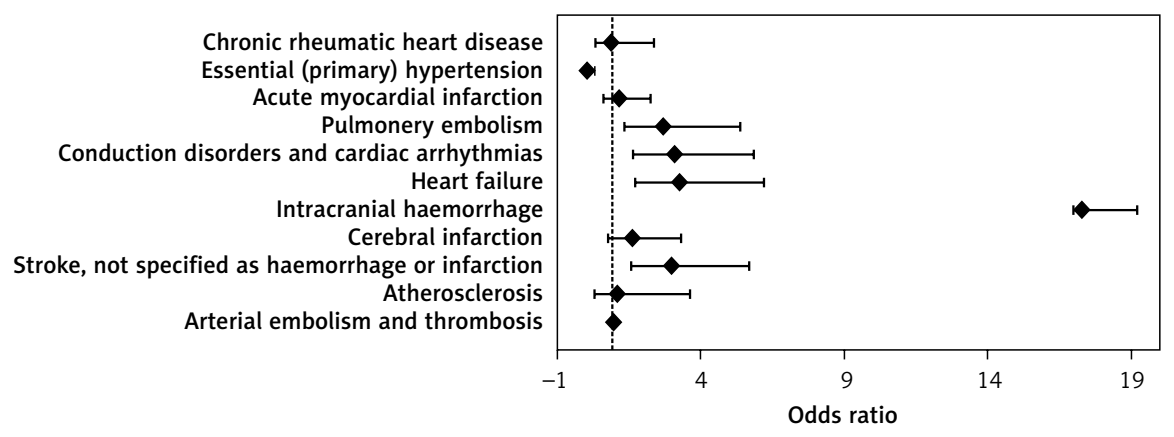

Figure 2. Odds ratios in death risk from atherosclerotic diseases using multiple logistic regression 
tionship between atherosclerosis and not only hypertension in females but also autoimmune diseases such as systemic lupus erythematosus, rheumatoid arthritis, and systemic sclerosis [2325]. Infections that have been proven to induce rheumatoid arthritis are involved in the pathogenesis of rheumatic autoimmune diseases and atherosclerotic diseases [24]. Another reason may be the misdiagnosis of atherosclerosis and therefore the subsequent treatment in women [26].

It is also worth noting that atherosclerotic diseases have been linked to lung cancer. The connecting link between cancer and atherosclerosis is the common molecular pathway and processes such as oxidative stress, inflammation, abnormal apoptosis, uncontrolled cell proliferation, and vasodilation, which are shared by these two multifactorial diseases. More specifically, degradation of cell proliferation, which is exacerbated by oxidative stress, allows not only the development of atherosclerotic plaque but also various types of cancer $[27,28]$.

In conclusion, the importance of this study lies in the emergence of the statistical significance characteristics of patients with atherosclerotic diseases as well as the atherosclerotic disease with the highest risk of death. It has been also identified a link between heart failure as well as cerebral infarction and lung cancer.

This study is not without limitations. A significant value of Pearson's $r$ does not imply causality between the variables, a fact that reflects the need for further studies in order to clarify the relationship between atherosclerotic diseases and lung cancer.

\section{Conflict of interest}

The author declare no conflict of interest.

\section{References}

1. Baigent C, Blackwell L, Emberson J, et al. Efficacy and safety of more intensive lowering of LDL cholesterol: a meta-analysis of data from 170,000 participants in 26 randomised trials. Lancet 2010, 376: 1670-81.

2. Di Angelantonio E, Sarwar N, Perry P, et al. Major lipids, apolipoproteins, and risk of vascular disease. JAMA 2009, 302: 1993-2000.

3. Fairweather D, Petri MA, Coronado MJ, Cooper LT, et al. Autoimmune heart disease: role of sex hormones and autoantibodies in disease pathogenesis. Expert Rev Clin Immunol 2012; 8: 269-84.

4. Fowkes FG, Housley E, Riemersma RA, et al. Smoking, lipids, glucose intolerance, and blood pressure as risk factors for peripheral atherosclerosis compared with ischemic heart disease in the Edinburgh Artery Study. Am J Epidemiol 1992; 135: 331-40.

5. International Consortium for Blood Pressure Genome-Wide Association Study. Genetic variants in novel pathways influence blood pressure and cardiovascular disease risk. Nature 2011, 478: 103-9.
6. Jaiswal S, Natarajan P, Silver AJ, et al. Clonal hematopoiesis and risk of atherosclerotic cardiovascular disease. N Engl J Med 2017; 377: 111-21.

7. Joosten MM, Pai JK, Bertoia ML, et al. Associations between conventional cardiovascular risk factors and risk of peripheral artery disease in men. JAMA 2012; 308: 1660-7.

8. Koene RJ, Prizment AE, Blaes A, et al. Shared risk factors in cardiovascular disease and cancer. Circulation 2016; 133: 1104-14.

9. Kravchenko J, Berry M, Arbeev K, et al. Cardiovascular comorbidities and survival of lung cancer patients: Medicare data based analysis. Lung Cancer 2015; 88: 85-93.

10. Lewington S, Clarke R, Qizilbash N, et al.; Prospective Studies Collaboration. Age-specific relevance of usual blood pressure to vascular mortality: a meta-analysis of individual data for one million adults in 61 prospective studies. Lancet 2002; 360: 1903-13.

11. Lewington S, Whitlock G, Clarke R, et al. Blood cholesterol and vascular mortality by age, sex, and blood pressure: a meta-analysis of individual data from 61 prospective studies with 55,000 vascular deaths. Lancet 2007; 370: 1829-39.

12. Li JJ, Fang CH, Chen MZ, et al. Activation of nuclear factor- $\mathrm{kB}$ and correlation with elevated $\mathrm{C}$-reactive protein in patients with unstable angina. Heart Lung Circ 2004; 13: 173-8.

13. Libby P. Inflammation in atherosclerosis. Nature 2002; 420: 868-74.

14. Lieb W, Jansen H, Loley C, et al. CARDIoGRAM. Genetic predisposition to higher blood pressure increases coronary artery disease risk. Hypertension 2013; 61: 9951001.

15. Masoudkabir F, Sarrafzadegan N, Gotay C, et al. Cardiovascular disease and cancer: evidence for shared disease pathways and pharmacologic prevention. Atherosclerosis 2017; 263: 343-51.

16. Meijer WT, Hoes AW, Rutgers D, et al. Peripheral arterial disease in the elderly: the Rotterdam Study. Arterioscler Thromb Vasc Biol 1998; 18: 185-92.

17. Pirie K, Peto R, Reeves GK, et al.; Million Women Study Collaborators. The 21st century hazards of smoking and benefits of stopping: a prospective study of one million women in the UK. Lancet 2013; 381: 133-41.

18. Regitz-Zagrosek V. Sex and gender differences in symptoms of myocardial ischaemia. Eur Heart J 2011; 32: 3064-6.

19. Roger VL, Go AS, Lloyd-Jones DM, et al. Heart disease and stroke statistics - 2011 update: a report from the American Heart Association. Circulation 2011; 104: 276-308.

20. Ross S, Gerstein HC, Eikelboom J, et al. Mendelian randomization analysis supports the causal role of dysglycaemia and diabetes in the risk of coronary artery disease. Eur Heart J 2015; 36: 1454-62.

21. Ross JS, Stagliano NE, Donovan MJ. Atherosclerosis and cancer: common molecular pathway of disease development and progression. Ann N Y Acad Sci 2001; 947: 271-92.

22. Sakao S, Tanabe N, Tatsumi K. The estrogen paradox in pulmonary arterial hypertension. Am J Physiol Lung Cell Mol Physiol 2010; 299: L435-8.

23. Sarwar N, Gao P, Seshasai SR, et al. Diabetes mellitus, fasting blood glucose concentration, and risk of vascular disease: a collaborative meta-analysis of 102 prospective studies. Lancet 2010; 375: 2215-22. 
24. Seshasai SR, Kaptoge S, Thompson A, et al. Diabetes mellitus, fasting glucose, and risk of cause-specific death. N Engl J Med 2011; 364: 829-41.

25. Singh GM, Danaei G, Farzadfar F, et al.; Global Burden of Metabolic Risk Factors of Chronic Diseases Collaborating Group; Asia-Pacific Cohort Studies Collaboration (APCSC); Diabetes Epidemiology: Collaborative analysis of Diagnostic criteria in Europe (DECODE); Emerging Risk Factor Collaboration (ERFC); Prospective Studies Collaboration (PSC). The age-specific quantitative effects of metabolic risk factors on cardiovascular diseases and diabetes: a pooled analysis. PLoS One 2013; 8: e65174.

26. Whitlock G, Lewington $S$, Sherliker $P$, et al. Body-mass index and cause-specific mortality in 900000 adults: collaborative analyses of 57 prospective studies. Lancet 2009; 373: 1083-96.

27. World Health Organization. Cardiovascular diseases. 2017, https://www.who.int/en/news-room/fact-sheets/ detail/cardiovascular-diseases-(cvds).

28. Yuan M, Li QG. Lung cancer and risk of cardiovascular disease: a meta-analysis of cohort studies. J Cardiothorac Vasc Anesth 2018; 32: e25-7. 